\title{
Bone Mineral Density in Children and Adolescents: Relation to Puberty, Calcium Intake, and Physical Activity*
}

\author{
ANNEMIEKE M. BOOT, MARIA A. J. DE RIDDER, HUIBERT A. P. POLS, \\ ERIC P. KRENNING, AND SABINE M. P. F. DE MUINCK KEIZER-SCHRAMA \\ Department of Pediatrics, Division of Endocrinology, Sophia Children's Hospital (A.B., S.M.K.S.), and \\ the Department of Epidemiology and Biostatistics (M.R.), Department of Internal Medicine, Division of \\ Endocrinology (H.P.), and Department of Nuclear Medicine (E.K.), Erasmus University, Rotterdam, \\ The Netherlands
}

\begin{abstract}
The association of height, weight, pubertal stage, calcium intake, and physical activity with bone mineral density (BMD) was evaluated in 500 children and adolescents (205 boys and 295 girls), aged 4-20 yr. The BMD (grams per $\mathrm{cm}^{2}$ ) of lumbar spine and total body was measured with dual energy x-ray absorptiometry. Lumbar spine volumetric BMD was calculated to correct for bone size. BMD and volumetric BMD increased with age. During puberty, the age-dependent increment was higher. After adjustment for age, the Tanner stage was significantly associated with all three BMD
\end{abstract}

variables in girls and with spinal BMD in boys. In boys, positive correlations were found between BMD and both calcium intake and physical activity after adjustment for age. Stepwise regression analysis with weight, height, Tanner stage, calcium intake, and physical activity as determinants with adjustment for age resulted in a model with Tanner stage in girls and weight in boys for all three BMD variables. The major independent determinant of BMD was the Tanner stage in girls and weight in boys. ( $J$ Clin Endocrinol Metab 82: 57-62, 1997)
D URING CHILDHOOD and adolescence, bone mineral density (BMD) increases until peak bone mass is reached (1). Peak bone mass and subsequent bone loss are important determinants of osteoporosis later in life (2). It is essential to know which factors influence BMD in childhood, with the goal of achieving optimal peak bone density. At present, dual energy $\mathrm{x}$-ray absorptiometry is the method of choice to measure BMD because of low radiation exposure, great precision, and accuracy (3).

In the present study, the BMDs of the lumbar spine and total body were measured in 500 children and adolescents. Small children were measured with special pediatric software, which is more precise than standard software (4). The volumetric BMD (BMAD) of the lumbar spine was calculated to correct for bone size. Lumbar spine mainly consists of trabecular bone, whereas the bone of the total body consists of $80 \%$ cortical bone (5). The BMDs of the lumbar spine and total body increase with age during childhood (6-11). It is controversial whether volumetric BMD increases with age (12-15).

The objective of this study was to gain reference values of BMD for healthy Dutch children and to evaluate the influence of age, weight, height, puberty, calcium intake, and physical activity on BMD.

Received May 29, 1996. Revision received August 21, 1996. Accepted August 26, 1996.

Address all correspondence and requests for reprints to: Dr. A. M. Boot, Sophia Children's Hospital, Division of Endocrinology, dr. Molewaterplein 60, 3015 GJ Rotterdam, the Netherlands.

* This work was supported by Novo Nordisk Farma.

\section{Subjects and Methods}

\section{Subjects}

A total of 500 children and adolescents between 4-20 yr of age were examined ( 205 boys and 295 girls). The ethnicity was Caucasian for 444 children (188 males), black for 21 children (7 males), and Asian for 35 children (9 males). The non-Caucasian children were analyzed as a separate group. The participants were recruited from three primary schools and two secondary schools of the city of Rotterdam in cooperation with the Organization of Child and Adolescent Welfare of Rotterdam. The study protocol was approved by the ethics committee of the University Hospital Rotterdam. Written informed consent was obtained from parents or from subjects older than $16 \mathrm{yr}$ of age.

\section{Methods}

A questionnaire was administered to all subjects to determine calcium intake, physical activity, vitamin and fluoride use, medical history, smoking, prematurity at birth, low birth weight, previous fractures, menarche, regularity of menstrual periods, use of oral contraceptives, and country of birth of both parents during an interview. The questions were asked of one of the parents and in the older children also of themselves. Calcium intake was determined by a detailed food frequency questionnaire of dairy products (16). Habitual physical activity included physical education classes, organized sports, recreational activity, and habitual walking and cycling and was measured in minutes per week (17). Children who were treated with oral corticosteroids, anticonvulsants, or heparin or who suffered from metabolic bone disease; disease of the kidneys, liver, or thyroid; diabetes mellitus; or cystic fibrosis were excluded from the study $(n=4)$. Height was measured with a fixed stadiometer. Weight was measured without shoes on a standard clinical balance.

As validated previously (18), pubertal development was evaluated by self-assessment of breast and pubic hair stage in girls and genitalia and pubic hair stage in boys, according to the method of Tanner (19). Subjects were given pictures and written descriptions, and selected the picture that most accurately reflected their appearance. When there were discrepancies between the two variables, greater emphasis was placed on 
the degree of breast development in girls and of genital development in boys for the determinations of Tanner stage.

BMD (grams per $\mathrm{cm}^{2}$ ) of lumbar spine and total body were measured by dual energy x-ray absorptiometry (DXA; Lunar DPXL/PED, Lunar Radiation Corp., Madison, WI). Pediatric software was used for children with a weight below $30 \mathrm{~kg}$. During measurement of the lumbar spine, the child was supine, and the physiological lumbar lordosis was flattened by elevation of the knees. All measurements were performed and analyzed by the same person (A.B.). Quality assurance was performed daily. The coefficient of variation has been reported to be $1.04 \%$ for spine BMD and $0.64 \%$ for total body BMD (20). The coefficient of variation was not determined, because it was considered unethical to measure a child several times. Of 43 children only, the BMD of the lumbar spine was measured.

The BMD (grams per $\mathrm{cm}^{2}$ ) from this measurement is an areal density that varies with bone size. Ancillary DXA-derived data were used to calculate apparent BMAD of the lumbar spine with the model BMAD = BMD $\times[4 /(\pi \times$ width $)]$. The lumbar body was assumed to have a cylindrical shape. The validity of this model was tested using in vivo volumetric data obtained from magnetic resonance imaging of lumbar vertebrae (21).

\section{Statistical analysis}

The best model for adjustment for age was chosen by multiple regression analysis. Multiple regression analysis was used to determine the association of various factors with BMD. Dummy variables were used for categorical variables that had more than two categories. Two sample $t$ tests were used to test differences in calcium intake and physical activity between boys and girls.

\section{Results}

The BMD of lumbar spine and total body and lumbar spine BMAD increased with age (Fig. 1 and Table 1). Due to the small number of subjects between 18-20 yr of age, they were combined in one group in Table 1. During puberty, the increment was higher than before puberty. The accumulation started to increase at the age of $11 \mathrm{yr}$ in girls and at the age of $13 \mathrm{yr}$ in boys. The variance increased during puberty. After the age of $16 \mathrm{yr}$, the age-dependent increase in BMD leveled off in girls, whereas in boys it continued. Girls had higher lumbar BMD and BMAD than boys at all ages. There was no difference in total body BMD between boys and girls.

The best model for adjustment for age resulted in a model for girls with the factors age, age $\mathrm{e}^{2}$, and age $^{3}$ and for boys with the factors age and age $\mathrm{e}^{2}$, for BMD as well as for BMAD. Adjustment for age was performed in this way unless reported otherwise.

The associations of the various factors with BMD and BMAD adjusted for age are listed in Table 2.

After adjustment for age, height had a significant positive association with lumbar spine and total body BMD in boys and with lumbar spine BMD in girls. Height had no significant association with BMAD in both sexes after adjustment for age.

Weight correlated significantly with all three BMD variables after adjustment for age.

Tanner stage had a significant positive association with BMD and BMAD of the lumbar spine and with total body BMD in boys and girls. The increases between the Tanner stages are shown in Table 3.

After adjustment for age, Tanner stage correlated still significantly with lumbar spine BMD and BMAD and total body BMD in girls (respectively, $P<0.001, P=0.001$, and $P<$ 0.001). The increases between Tanner stage III to IV and IV to $\mathrm{V}$ were significant in girls for all three BMD variables adjusted for age.

After adjustment for age, Tanner stage correlated significantly with lumbar spine BMD $(P=0.03)$, but not with total body BMD or lumbar spine BMAD in boys.

One hundred and forty-three girls had experienced menarche. Girls of the same age who had experienced menarche had higher lumbar spine and total body BMD and spinal BMAD than girls who had not. To evaluate whether the age at menarche influenced BMD, an analysis was performed of the girls who had experienced menarche with adjustment for age. An earlier age at menarche was associated with a higher $\mathrm{BMD}$ (regression coefficient $=0.0032$ for lumbar spine BMD and 0.0025 for total body BMD; both $P<0.001$ ). There was no significant association for BMAD. The girls with regular periods had higher total body BMD than girls with irregular periods (regression coefficient $=0.043$; $P=0.01$ ) independent of age. For lumbar spine BMD and BMAD, the difference did not reach significance (respectively, $P=0.06$ and $P=0.96)$.

The mean calcium intake of the Caucasian children was $1180 \mathrm{mg} /$ day $(\mathrm{sD}=516)$. There was no significant difference in calcium intake between boys and girls and no significant correlation with age.

Calcium intake had no significant association with BMD in girls. In boys, calcium intake was positively correlated to total body BMD $(P<0.01)$ independent of age; the effect did not reach significance for lumbar spine BMD $(P=0.12)$.

Calcium intake had no significant association with lumbar spine BMAD in either sex.

Physical activity was significantly higher in boys than in girls [mean, $9.1(\mathrm{sD}=5.4)$ vs. $7.5(\mathrm{sD}=4.0) \mathrm{h} /$ week; $P<$ 0.001]. Physical activity had no significant association with BMD and BMAD in girls. In boys, physical activity had a significant positive correlation with lumbar spine $(P<0.05)$ and total body $(P<0.05)$ BMD after adjustment for age, but not with lumbar spine BMAD.

Ethnicity had no significant association with BMD or BMAD in boys. In girls, ethnicity had a significant influence on total body BMD. The girls of Asian ethnicity had a lower total body BMD than the Caucasian girls. The BMD and BMAD of the children with black ethnicity did not differ from those of the other children.

The children with Asian ethnicity had a significantly lower calcium intake than the Caucasian children (759 vs. 1180 $\mathrm{mg}$ /day). The Asian girls had a significantly lower physical activity (4.9 vs. $7.5 \mathrm{~h} /$ week) than the Caucasian girls. The physical activity of the Asian boys was not significantly different. The calcium intake and physical activity of black children were not significantly different from those of Caucasian children.

A history of prematurity $(\mathrm{n}=18)$ or low birth weight $(n=24)$, smoking $(n=32)$, two or more fractures in the past $(n=22)$, use of oral contraceptives $(n=30)$, and the use of vitamins $(n=126)$ or fluoride $(n=69)$ were not associated with BMD or BMAD.

Stepwise forward selection in multiple regression analysis with weight, height, Tanner stage, calcium intake, and physical activity as determinants with adjustment for age and with BMD as the dependent variable resulted in a model with 

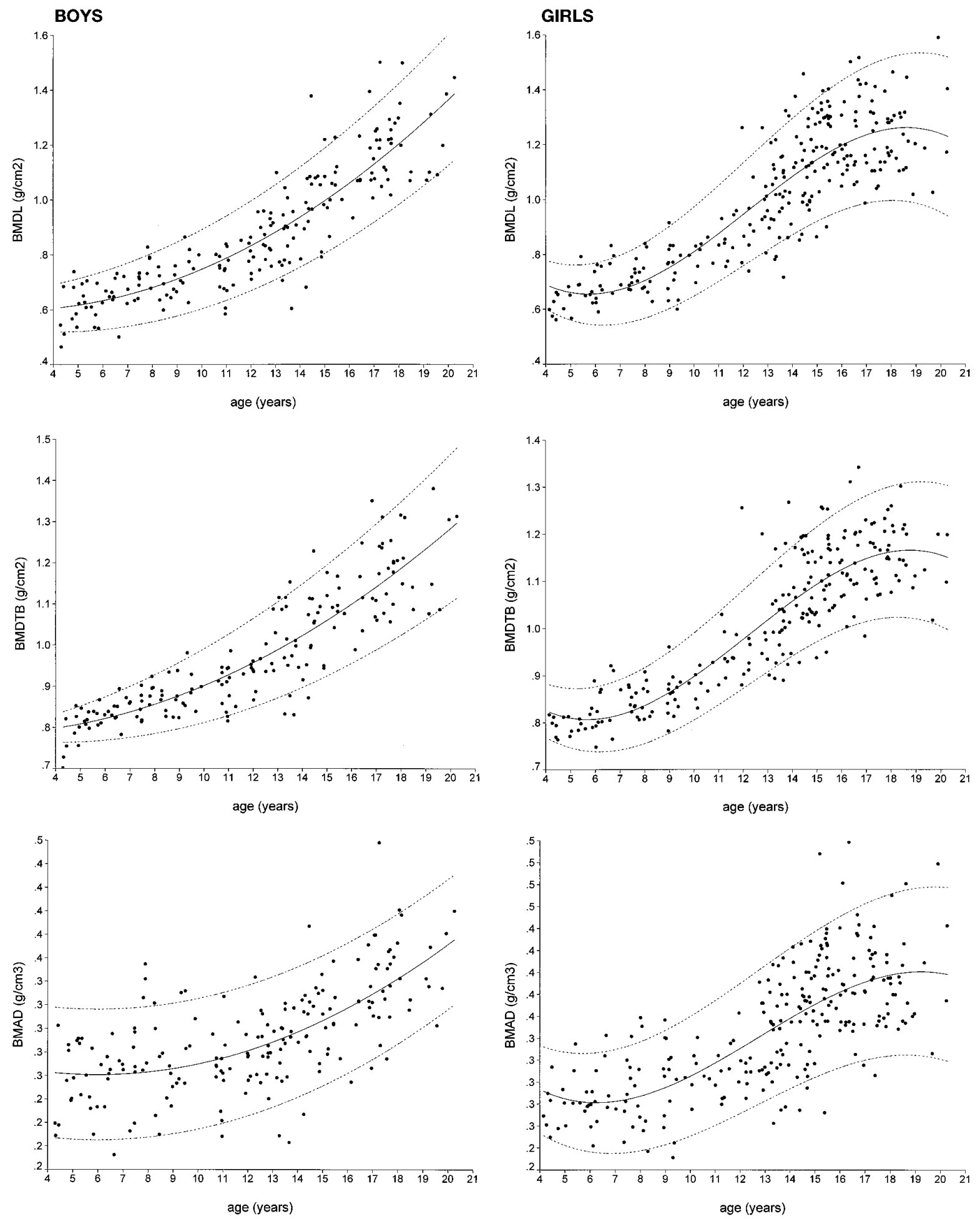

FIG. 1. Relation between age and BMD of the lumbar spine (BMDL; grams per $\left.\mathrm{cm}^{2}\right)$, total body BMD (BMDTB; grams per $\left.\mathrm{cm}^{2}\right)$, and BMAD of the lumbar spine $\left(\right.$ grams per $\left.\mathrm{cm}^{3}\right)$ in boys and girls. The line shows the best-fitted function with the factors age, age $\mathrm{e}^{2}$, and age $\mathrm{e}^{3}$ for girls and age and age ${ }^{2}$ for boys. The dotted lines represent the $5 \%$ and $95 \%$ prediction limits.

weight and Tanner stage for lumbar spine BMD in girls and explained $80 \%$ of the variance. The factors weight and Tanner stage had a significant influence on total body BMD $\left(\mathrm{r}^{2}=\right.$ $85 \%)$, and the factor Tanner stage had a significant influence on lumbar spine BMAD of girls $\left(r^{2}=57 \%\right)$.
The model for lumbar spine BMD of boys included the factors weight and height $\left(\mathrm{r}^{2}=85 \%\right)$. Weight and calcium intake were the factors with a significant influence on total body BMD of boys $\left(r^{2}=88 \%\right)$. The model for BMAD of boys included the factor weight $\left(\mathrm{r}^{2}=46 \%\right)$. 
TABLE 1. Mean BMD values of lumbar spine (BMDL; grams per $\mathrm{cm}^{2}$ ), BMAD of lumbar spine (grams per $\mathrm{cm}^{3}$ ), BMD of total body (BMDTB; grams per $\mathrm{cm}^{2}$ ), and SDs in boys and girls

\begin{tabular}{|c|c|c|c|c|c|c|c|c|}
\hline Age (yr) & $\mathrm{n}$ & BMDL & $\mathrm{SD}$ & BMAD & SD & $\mathrm{n}$ & BMDTB & SD \\
\hline \multicolumn{9}{|l|}{ Boys } \\
\hline $4-5$ & 9 & 0.591 & 0.09 & 0.250 & 0.03 & 9 & 0.781 & 0.05 \\
\hline $5-6$ & 12 & 0.625 & 0.06 & 0.261 & 0.03 & 12 & 0.826 & 0.02 \\
\hline $6-7$ & 10 & 0.656 & 0.07 & 0.260 & 0.03 & 10 & 0.843 & 0.03 \\
\hline $7-8$ & 13 & 0.720 & 0.06 & 0.282 & 0.04 & 13 & 0.866 & 0.03 \\
\hline $8-9$ & 11 & 0.685 & 0.05 & 0.261 & 0.03 & 11 & 0.870 & 0.04 \\
\hline $9-10$ & 8 & 0.755 & 0.08 & 0.288 & 0.03 & 8 & 0.892 & 0.05 \\
\hline $10-11$ & 11 & 0.726 & 0.08 & 0.257 & 0.03 & 11 & 0.894 & 0.05 \\
\hline $11-12$ & 9 & 0.791 & 0.07 & 0.282 & 0.03 & 9 & 0.929 & 0.04 \\
\hline $12-13$ & 18 & 0.846 & 0.08 & 0.282 & 0.03 & 10 & 0.961 & 0.07 \\
\hline $13-14$ & 17 & 0.868 & 0.13 & 0.280 & 0.03 & 15 & 0.998 & 0.10 \\
\hline $14-15$ & 16 & 0.977 & 0.17 & 0.306 & 0.04 & 15 & 1.030 & 0.09 \\
\hline $15-16$ & 12 & 1.058 & 0.10 & 0.312 & 0.03 & 9 & 1.111 & 0.04 \\
\hline $16-17$ & 11 & 1.119 & 0.12 & 0.319 & 0.03 & 9 & 1.133 & 0.11 \\
\hline $17-18$ & 19 & 1.204 & 0.11 & 0.347 & 0.04 & 17 & 1.187 & 0.08 \\
\hline $18-20$ & 12 & 1.238 & 0.16 & 0.355 & 0.03 & 11 & 1.202 & 0.11 \\
\hline \multicolumn{9}{|l|}{ Girls } \\
\hline $4-5$ & 9 & 0.624 & 0.04 & 0.278 & 0.02 & 9 & 0.795 & 0.02 \\
\hline $5-6$ & 9 & 0.674 & 0.07 & 0.288 & 0.02 & 9 & 0.810 & 0.03 \\
\hline $6-7$ & 11 & 0.708 & 0.08 & 0.288 & 0.03 & 11 & 0.828 & 0.06 \\
\hline $7-8$ & 14 & 0.710 & 0.03 & 0.290 & 0.03 & 14 & 0.843 & 0.03 \\
\hline $8-9$ & 11 & 0.749 & 0.10 & 0.301 & 0.05 & 11 & 0.860 & 0.05 \\
\hline $9-10$ & 9 & 0.745 & 0.08 & 0.296 & 0.04 & 9 & 0.863 & 0.03 \\
\hline $10-11$ & 8 & 0.767 & 0.10 & 0.297 & 0.04 & 8 & 0.863 & 0.07 \\
\hline $11-12$ & 11 & 0.887 & 0.14 & 0.313 & 0.03 & 11 & 0.969 & 0.11 \\
\hline $12-13$ & 15 & 0.950 & 0.13 & 0.327 & 0.03 & 10 & 0.974 & 0.09 \\
\hline $13-14$ & 30 & 1.024 & 0.15 & 0.345 & 0.04 & 25 & 1.021 & 0.09 \\
\hline $14-15$ & 32 & 1.121 & 0.15 & 0.364 & 0.04 & 30 & 1.081 & 0.07 \\
\hline $15-16$ & 28 & 1.239 & 0.12 & 0.396 & 0.04 & 23 & 1.126 & 0.08 \\
\hline $16-17$ & 26 & 1.230 & 0.15 & 0.392 & 0.05 & 23 & 1.143 & 0.09 \\
\hline $17-18$ & 22 & 1.214 & 0.11 & 0.390 & 0.03 & 21 & 1.156 & 0.06 \\
\hline $18-20$ & 21 & 1.246 & 0.15 & 0.397 & 0.05 & 20 & 1.159 & 0.07 \\
\hline
\end{tabular}

TABLE 2. Association of various factors with lumbar spine BMD (BMDL; grams per $\left.\mathrm{cm}^{2}\right)$, total body BMD (BMDTB; grams per $\mathrm{cm}^{2}$ ), and lumbar spine BMAD (grams per $\mathrm{cm}^{3}$ ) after adjustment for age

\begin{tabular}{|c|c|c|c|c|}
\hline & \multicolumn{2}{|c|}{ Boys } & \multicolumn{2}{|c|}{ Girls } \\
\hline & $\begin{array}{c}\text { Regression coefficient } \\
(1 / 1000)\end{array}$ & $P$ value & $\begin{array}{c}\text { Regression coefficient } \\
(1 / 1000)\end{array}$ & $P$ value \\
\hline \multicolumn{5}{|l|}{$\mathrm{Ht}(\mathrm{cm})$} \\
\hline BMDL & 7.04 & $<0.001$ & 3.62 & 0.002 \\
\hline BMDTB & 3.53 & $<0.001$ & 0.79 & NS \\
\hline BMAD & 0.31 & NS & 0.42 & NS \\
\hline \multicolumn{5}{|l|}{$\mathrm{Wt}(\mathrm{kg})$} \\
\hline BMDL & 5.48 & $<0.001$ & 5.73 & $<0.001$ \\
\hline BMDTB & 5.40 & $<0.001$ & 5.15 & $<0.001$ \\
\hline BMAD & 0.63 & 0.02 & 0.75 & 0.01 \\
\hline \multicolumn{5}{|c|}{ Calcium intake $(\times 100 \mathrm{mg} /$ day $)$} \\
\hline BMDL & 2.57 & NS & 1.07 & NS \\
\hline BMDTB & 2.95 & 0.009 & 0.74 & NS \\
\hline BMAD & 0.50 & NS & 0.05 & NS \\
\hline \multicolumn{5}{|c|}{ Physical activity (h/week) } \\
\hline BMDL & 3.11 & 0.04 & 0.17 & NS \\
\hline BMDTB & 2.11 & 0.04 & 0.06 & NS \\
\hline BMAD & 0.23 & NS & 0.03 & NS \\
\hline
\end{tabular}

\section{Discussion}

In this study determinants of BMD were evaluated in 500 healthy children and adolescents. Weight in boys and Tanner stage in girls had a significant and independent correlation with all three BMD variables.

Determinants of BMD in healthy persons are geneticethnic factors, hormonal status, calcium intake, physical activity, and weight. Forty-six to $62 \%$ of the variance in BMD could be attributed to genetic factors in a study with parents and their children (22). Twin studies showed a higher heritability, up to $80 \%(23,24)$. This might be an overestimation as a result of more common lifestyle factors.

Bone density is higher in black than in white subjects and lower in Chinese and Japanese $(25,26)$. We found a lower total body BMD of girls of Asian ethnicity than of Caucasian girls. The lower bone density in Asians might be attributed to low calcium intake (26). Calcium supplementation in- 
TABLE 3. Mean BMD $( \pm \mathrm{SD})$ of lumbar spine (BMDL) and total body (BMDTB) and BMAD per Tanner stage

\begin{tabular}{|c|c|c|c|c|c|c|c|c|}
\hline \multirow{2}{*}{$\begin{array}{l}\text { Tanner } \\
\text { stage }\end{array}$} & \multicolumn{4}{|c|}{ Boys } & \multicolumn{4}{|c|}{ Girls } \\
\hline & $\mathrm{n}$ & BMDL & BMDTB & BMAD & $\mathrm{n}$ & BMDL & BMDTB & BMAD \\
\hline I & 79 & $0.69 \pm 0.09$ & $0.86 \pm 0.06$ & $0.27 \pm 0.03$ & 67 & $0.71 \pm 0.08$ & $0.84 \pm 0.05$ & $0.29 \pm 0.03$ \\
\hline II & 24 & $0.82 \pm 0.10^{a}$ & $0.94 \pm 0.07^{a}$ & $0.28 \pm 0.03$ & 14 & $0.83 \pm 0.07^{b}$ & $0.93 \pm 0.05^{a}$ & $0.30 \pm 0.01$ \\
\hline III & 14 & $0.91 \pm 0.15^{c}$ & $1.02 \pm 0.10^{c}$ & $0.29 \pm 0.04$ & 21 & $0.96 \pm 0.15^{b}$ & $0.97 \pm 0.08$ & $0.33 \pm 0.04$ \\
\hline IV & 46 & $1.08 \pm 0.17^{d}$ & $1.11 \pm 0.12^{b}$ & $0.32 \pm 0.04^{b}$ & 74 & $1.14 \pm 0.15^{d}$ & $1.08 \pm 0.09^{d}$ & $0.37 \pm 0.04^{d}$ \\
\hline V & 26 & $1.17 \pm 0.14^{b}$ & $1.15 \pm 0.09^{c}$ & $0.34 \pm 0.04^{c}$ & 79 & $1.22 \pm 0.14^{d}$ & $1.15 \pm 0.08^{d}$ & $0.39 \pm 0.04^{a}$ \\
\hline
\end{tabular}

${ }^{a} P<0.001$ vs. previous stage.

${ }^{b} P<0.01$ vs. previous stage.

${ }^{c} P<0.05$ vs. previous stage.

${ }^{d} P<0.0001$ vs. previous stage.

creased the bone mineral content of Chinese children with habitually low calcium intakes (27).

Our values for lumbar spine BMD are higher than published values of Finnish children (13) and comparable to those of Spanish children (6) measured using DXA equipment from the same manufacturer. There may be geographical differences in BMD. A study in adults found higher incidence rates of hip fractures in the northern part of Europe compared to the rest of Europe (28).

During puberty, there was a large increase in BMD and BMAD. Lumbar spine BMD and BMAD and total body BMD increased significantly with higher Tanner stages, as was previously found for lumbar spine $\operatorname{BMD}(6,10,29)$ and total body BMD (7). During puberty, GH as well as sex steroid levels increase, and both have a positive influence on BMD $(30,31)$. The influence of puberty on BMD was higher in girls than in boys. In multiple regression analysis, Tanner stage did not correlate significantly with BMD in boys, whereas in girls it was the major determinant. Animals studies showed a more important role of estrogen than of androgen in mineralization of the skeleton (32). Estrogen is an important determinant of BMD in girls during puberty. This is illustrated by our results showing that girls who had an early menarche or regular periods had higher BMD. Other studies showed that late menarche and amenorrhea in ballet dancers and patients with anorexia nervosa were related to a reduced BMD and fractures (33-36). Late puberty and amenorrhea are risk factors for low BMD in girls.

A few studies showed that persons who consume greater quantities of calcium early in life have greater bone mass later $(37,38)$. Peak bone mass is optimal when the threshold calcium balance is met (39). The threshold is the level of calcium intake below which skeletal accumulation of calcium varies with intake and above which it remains constant. According to Matkovic et al. (39), the threshold values are higher than the recommended dietary allowances for calcium $(800 \mathrm{mg} /$ day during childhood and $1200 \mathrm{mg} /$ day during adolescence). The mean calcium intake in our study was 1180 $\mathrm{mg} /$ day.

Johnston et al. (40) showed that calcium supplementation (1000 mg calcium/day) enhanced the rate of increase in BMD in prepubertal children. This study was a 3-yr, double blind, placebo-controlled trial in 70 pairs of identical twins. The increase in BMD was twice as high at the radius (cortical bone) as at the lumbar spine (trabecular bone). We also found a higher correlation between calcium intake and total body
BMD, which mainly consists of cortical bone, than between calcium intake and lumbar spine BMD in boys.

An adequate calcium intake during childhood is important for optimal mineralization of the skeleton.

Slemenda et al. (41) found that the total hours of weightbearing activity per week was positively correlated to BMD of the radius and hip in boys and girls 5-14 yr of age. Other studies found a positive correlation between physical activity and lumbar spine BMD (42) or femoral neck BMD (13) in children. In a prospective study it was found that the men and women with the highest levels of exercise at the age of 9-18 yr had higher femoral BMD at the age of 20-29 yr than those with the lowest levels; only the men with the highest levels of exercise had also higher BMD of the lumbar spine (43). In our study, physical activity had a positive association with BMD in boys only. The low variance in physical activity in girls may be the reason why no association was found between physical activity and BMD in girls.

The effect of weight on BMD is due to load on weightbearing bones (44), comparable to the influence of physical activity. Children who are underweight and inactive are at risk of developing low BMD.

DXA measures bone mineral content within the projected area; the correction for area removes some, but not all, of the dependence on bone size. To correct completely for bone size, we calculated volumetric density for the lumbar spine; this was not possible for the total body measurement. Bone size might be an independent determinant of bone strength $(45,46)$. Studies showed the relation between areal BMD and both strength (47) and fracture risk (48), which justifies the use of areal BMD. Diagnostic sensitivity was higher, and precision error was lower for BMD than for BMAD in postmenopausal women (46). Data for the true volumetric density of children are scarce, because of the high radiation dose of quantitative computed tomography. A study of true volumetric spinal bone density measured by quantitative computed tomography showed no increase between 2 and $12 \mathrm{yr}$ in girls (12). Kröger et al. (13) and Lu et al. (15) found a significant age-dependent increase in calculated lumbar spine BMAD in girls and boys. Our results also showed an increase in BMAD with age.

Height, calcium intake, and physical activity had no significant influence on spinal BMAD; therefore, the influence of these variables on spinal BMD could be due to an increase in bone size.

This cross-sectional study provides reference values for 
lumbar spine and total body BMD of children and adolescents of a West-European country. Lumbar spine and total body BMD and lumbar spine BMAD increase with age, with a higher increment during puberty. Determinants of BMD are age, sex, genetic-ethnic factors, hormonal status, calcium intake, physical activity, and weight. The major determinant of BMD during childhood appeared to be weight in boys and pubertal development in girls.

\section{Acknowledgments}

The authors thank Peter P. M. Kooy and Jopie Hensen of the Department of Nuclear Medicine for their cooperation; Gijs Willem van Omme, Hein Raat, and Alice A. J. M. Hazebroek-Kampschreur of the Child and Adolescent Welfare Organization of Rotterdam for assistance with the recruiting of the children, and medical students Gerwin Wildeboer and Jeroen van Essen for their assistance.

\section{References}

1. Ott SM. 1990 Attainment of peak bone mass [Editorial]. J Clin Endocrinol Metab. 71:1082.

2. Hansen MA, Overgaard K, Riis BJ, Christiansen C. 1991 Role of peak bone mass and bone loss in postmenopausal osteoporosis: 12 year study. Br Med J. 303:961-964.

3. Mazess RB, Barden HS, Bisek JP, Hanson J. 1990 Dual energy x-ray absorptiometry for total body and regional bone mineral density and soft tissue composition. Am J Clin Nutr. 51:1106-1112.

4. Slosman DO, Rizzoli R, Bonjour JP. 1995 Bone absorptiometry: a critical appraisal of various methods. Acta Paediatr Supp. 411:9-11.

5. Martin TJ, Kong Wah NG, Nicholson GC. 1988 The biology of bone. Baillieres Clin Endocrinol Metab. 2:1.

6. Rio del L, Carrascosa A, Pons F, Gusinye M, Yeste D, Domenech FM. 1994 Bone mineral density of the lumbar spine in white Mediterranean Spanish children and adolescents: changes related to age, sex and puberty. Pediatr Res. 35:362-366.

7. Rico H, Revilla M, Villa LF, Hernandez ER, Alvarez de Buergo M, Villa M. 1993 Body composition in children and Tanner 's stages: a study with dual energy x-ray absorptiometry. Metabolism. 8:967-970.

8. Lu WP, Briody JN, Ogle GD, et al. 1994 Bone mineral density of total body, spine and femoral neck in children and young adults: a cross-sectional and longitudinal study. J Bone Miner Res. 9:1451-1458.

9. Southard RN, Morris JD, Mahan JD, et al. 1991 Bone mass in healthy children measurement with quantitative DXA. Radiology. 179:735-738.

10. Zanchetta JR, Plotkin H, Filgueira MLA. 1995 Bone mass in children: normative values for the 2-20 year-old population. Bone. 16:393S-399S.

11. Plotkin H, Nunez M, Alvarez Filguera ML, Zanchetta JR. 1996 Lumbar spine bone density in Argentine children. Calcif Tissue Int. 58:144-149.

12. Gilsanz V, Gibbens DT, Roe TF, et al. 1988 Vertebral bone density in children: effect of puberty. Radiology. 166:847-850.

13. Kröger H, Kotameini A, Vainio P, Alhava E. 1992 Bone densitometry of the spine and femur in children by dual-energy $\mathrm{x}$-ray absorptiometry. Bone Miner. 17:75-85.

14. Schönau E, Wentzik U, Michalk D, Scheidhauer K, Klein K. 1993 Is there an increase of bone density in children? Lancet. 342:689-690.

15. Lu PW, Cowell CT, Lloyd-Jones SA, Briody JN, Howman-Giles R. 1996 Volumetric bone mineral density in normal subjects, aged 5-27 years. J Clin Endocrinol Metab. 81:1586-1590.

16. Angus RM, Sambrook PN, Pocock NA, Eisman JA. 1989 A simple method for assessing calcium intake in Caucasian women. J Am Diet Assoc. 89:209-214

17. Verschuur R, Kemper HCG. 1985 Habitual physical activity. Med Sport Sci. 20:55-65.

18. Duke PM, Litt IF, Gross RT. 1980 Adolescents' self-assessment of sexual maturation. Pediatrics. 66:918-920.

19. Tanner JM. 1962 Growth at adolescence, 2nd ed. Oxford: Blackwell.

20. Johnson J, Dawson-Hughes B. 1991 Precision and stability of dual energy x-ray absorptiometry measurements. Calcif Tissue Int. 49:174-178.

21. Kröger H, Vainio P, Nieminen J, Kotaniemi A. 1995 Comparison of different models for interpreting bone mineral density measurements using DXA and MRI technology. Bone. 17:157-159.
22. Krall EA, Dawson-Hughes B. 1993 Heritable and lifestyle determinants of bone mineral density. J Bone Miner Res. 8:1-9.

23. Dequeker J, Nijs J, Verstraeten A, Gensens P, Gevers G. 1987 Genetic determinants of bone mineral content at the spine and radius: a twin study. Bone. 8:207-209.

24. Pocock NA, Eisman JA, Hopper JL, Yeates MG, Sambrook PN, Eberl S. 1987 Genetic determinants of bone mass in adults. A twin study. J Clin Invest. 80:706-710.

25. Luckey MM, Meier DE, Mandeli JP, DaCosta MC, Hubbard ML, Goldsmith SJ. 1989 Radial and vertebral bone density in white and black women: evidence for racial differences in premenopausal bone homeostasis. J Clin Endocrinol Metab. 69:762-770.

26. Pollitzer WS, Anderson JJB. 1989 Ethnic and genetic differences in bone mass: a review with a hereditary vs environmental perspective. Am J Clin Nutr. 50:1244-1259.

27. Lee WTK, Leung SSF, Wang S, et al. 1994 Double-blind, controlled calcium supplementation and bone mineral accretion in children accustomed to a low calcium diet. Am J Clin Nutr. 60:744-750.

28. Johnell O, Gullberg B, Allander E, Kanis JA. 1992 The apparent incidence of hip fracture in Europe: a study of national register sources. MEDOS Study Group. Osteoporosis Int. 2:298-302.

29. Glastre C, Braillon P, David L, Cochat P, Meunier PJ, Delmas PD. 1990 Measurement of bone mineral content of the lumbar spine by dual energy x-ray absorptiometry in normal children: correlations with growth parameters. J Clin Endocrinol Metab. 70:1330-1333.

30. Albertsson-Wikland K, Rosberg S, Karlberg J, Groth T. 1994 Analysis of 24-hour growth hormone profiles in healthy boys and girls of normal stature: relation to puberty. J Clin Endocrinol Metab. 78:1195-1201.

31. Slootweg MC. 1993 Growth hormone and bone. Horm Metab Res. 25:335-343.

32. Frank GR. 1995 The role of estrogen in pubertal skeletal physiology: epiphyseal maturation and mineralization of the skeleton. Acta Paediatr. 84:627-630.

33. Warren MP, Brooks-Gunn J, Hamilton LH, Warren F, Hamilton WG. 1986 Scoliosis and fractures in young ballet dancers. N Engl J Med. 314:1348-1353.

34. Bachrach LK, Katzman DK, Litt IF, Guido D, Marcus R. 1991 Recovery from osteopenia in adolescent girls with anorexia nervosa. J Clin Endocrinol Metab. 72:602-606

35. Hergenroeder AC. 1995 Bone mineralization, hypothalamic amenorrhea, and sex steroid therapy in female adolescents and young adults. J Pediatr. 126:683-689.

36. Young N, Formica C, Szmukler G, Seeman E. 1994 Bone density at weightbearing and nonweight-bearing sites in ballet dancers: the effects of exercise, hypogonadism and body weight. J Clin Endocrinol Metab. 78:449-454.

37. Murphy S, Khaw KT, May H, Compston JE. 1994 Milk consumption and bone mineral density in middle aged and elderly women. Br Med J. 308:939-941.

38. Sandler RB, Slemenda CW, La Porte RE. 1985 Postmenopausal bone density and milk consumption in childhood and adolescence. Am J Clin Nutr. 42:270-274.

39. Matkovic V. 1992 Calcium intake and peak bone mass. N Engl J Med. 327:119-120.

40. Johnston CC, Miller JZ, Slemenda CW, et al. 1992 Calcium supplementation and increases in bone mineral density in children. N Engl J Med. 327:82-87.

41. Slemenda CW, Miller JZ, Hui SL, Reister TK, Johnston CC. 1991 Role of physical activity in the development of skeletal mass in children. J Bone Miner Res. 6:1227-1233.

42. Rubin K, Schirduan V, Gendreau P, Sarfarazi M, Mendola R, Dalsky G. 1993 Predictors of axial and peripheral bone mineral density in healthy children and adolescents, with special attention to the role of puberty. J Pediatr. 123:863-870.

43. Välimäki MJ, Kärkkäinen M, Lamberg-Allardt C, et al. 1994 Exercise, smoking and calcium intake during adolescence and early adulthood as determinants of peak bone mass. Br Med J. 309:230-235.

44. Felson DT, Zhang Y, Hannan MT, Anderson JJ. 1993 Effects of weight and body mass index on bone mineral density in men and women: the Framingham study. J Bone Miner Res. 8:567-573.

45. Compston JE. 1995 Bone density: BMC, BMD or corrected BMD? Bone. 16:5-7.

46. Mazess RB, Barden H, Mautalen C, Vega E. 1994 Normalization of spine densitometry. J Bone Miner Res. 9:541-548.

47. Moro M, Hecker AT, Bouxsein ML, Myers ER. 1995 Failure load of thoracic vertebrae correlates with lumbar bone mineral density measures with DXA Calcif Tissue Int. 56:206-209.

48. Cummings SR, Black DM, Nevitt MC, et al. 1993 Bone density of various sites for prediction of hip fractures. Lancet. 341:72-75. 